\title{
Role of diagnostic hysteroscopy in abnormal uterine bleeding
}

\author{
Swati Singh $^{1}$, Bal Krishan Taneja ${ }^{1}$, Prem Singh ${ }^{2}$, Ravinder Ahlawat ${ }^{3}$
}

\author{
${ }^{1}$ Department of Obstetrics \& Gynaecology, MMIMSR, Mullana, Ambala, Haryana, India \\ ${ }^{2}$ Department of Pathology, MMIMSR, Mullana, Ambala, Haryana, India \\ ${ }^{3}$ M.B.B.S., MHA, AIIMS, Delhi, India
}

Received: 3 June 2014

Accepted: 1 July 2014

\author{
*Correspondence: \\ Dr. Swati Singh, \\ E-mail: swatisingh0011@gmail.com
}

(C) 2014 Singh S et al. This is an open-access article distributed under the terms of the Creative Commons Attribution Non-Commercial License, which permits unrestricted non-commercial use, distribution, and reproduction in any medium, provided the original work is properly cited.

\begin{abstract}
Background: The objective of the study was to correlate hysteroscopic findings with histopathological findings in women with abnormal uterine bleeding and to study the accuracy of hysteroscopy in abnormal uterine bleeding.

Methods: Settings: tertiary care hospital. Study design: prospective study. A prospective study was carried out in the Department of Obstetrics and Gynaecology at MMIMSR, Mullana, Ambala, from May 2011 to September 2013. 100 cases were selected for this study from patients who were admitted with history of abnormal uterine bleeding. Hysteroscopic examination was done in all patients post-menstrually, whenever possible, except in those cases where menstrual cycles were grossly irregular or patients came with continuous bleeding per vaginum. The patients then underwent dilatation and curettage and curettings was sent for histopathological examination. The correlation between findings on hysteroscopy and histopathological examination was done.

Results: On hysteroscopy, $48 \%$ of the patients had either proliferative or secretory picture which was grouped as normal. The rest $52 \%$ of patients had some abnormality. Hyperplasia was the most common finding which was seen in $26 \%$ patients. The other findings included endometrial polyp $8 \%$, myoma or myomatous polyp $7 \%$, atrophic endometrium 4\%, endometrial carcinoma, misplaced IUCD, and synechiae comprising $2 \%$ each and tubercular endometritis $1 \%$.

Conclusions: Hysteroscopy has a high sensitivity i.e. it can supplement and enhance the accuracy of tissue diagnosis. So, hysteroscopically directed biopsy would be an ideal procedure in abnormal uterine bleeding wherever facilities are available.
\end{abstract}

Keywords: Abnormal uterine bleeding, Dilatation and curettage, Hysteroscopy

\section{INTRODUCTION}

Abnormal Uterine Bleeding (AUB) is one of the most common gynaecological disorders. AUB affects 10 to $30 \%$ of reproductive aged women and up to $50 \%$ of perimenopausal women. ${ }^{1}$ The menstrual disorders were the reason for $19.1 \%$ of 20.1 million visits to physician clinics for gynaecological conditions over a period of two years. $^{2}$ Furthermore, $25 \%$ of gynaecologic surgeries involve abnormal uterine bleeding. ${ }^{3}$ The causes which lead to the abnormal uterine bleeding include hormonal imbalance, uterine myoma, endometrial polyps, pregnancy related complications, adenomyosis, endometriosis and endometrial carcinoma. The traditional methods of evaluation include good history taking, clinical examination and histopathological examination of the endometrial sample obtained by dilatation and curettage. Despite of all this, the etiology remains illunderstood in many cases until a major surgical intervention is done. This necessitates improved diagnostic methods for its evaluation which will permit greater precision in its diagnosis. The diagnostic procedure must be safe and should also withstand critical and factual evaluation of its accuracy. The current 
practice of investigating abnormal uterine bleeding has been challenged for its accuracy, complications and costeffectiveness.

Out of the various diagnostic techniques, for many years, dilatation and curettage has been the gold standard for evaluating the patients with abnormal uterine bleeding. Although the diagnosis may be obtained in this manner in most patients, yet in about $10 \%$ of patients evaluated by the blind curettage; may miss focal pathology. ${ }^{4,5}$ Polyps and submucous fibroids are frequently undetected by curettage alone. ${ }^{6}$ The fallacies of curettage suggest the need for better methods of evaluation of abnormal uterine bleeding. Other diagnostic techniques used in AUB are hysteroscopy, transvaginal sonography, laparoscopy etc. Thus, the traditional dilatation and curettage should now be replaced by hysteroscopy followed by curettage.

The present study was undertaken to analyse the role of diagnostic hysteroscopy in evaluating cases with abnormal uterine bleeding and to study the accuracy of hysteroscopy in evaluation of abnormal uterine bleeding.

\section{Aims and objectives}

1. To correlate hysteroscopic findings with histopathologic findings in women with abnormal uterine bleeding.

2. To study the accuracy of hysteroscopy in evaluation of abnormal uterine bleeding.

\section{METHODS}

This study was conducted on 100 women with abnormal uterine bleeding from the outpatient/inpatient, department of obstetrics and gynaecology of Maharishi Markendeshwar institute of medical sciences and research, Mullana, Ambala from May 2011 to September 2013. It is a prospective study.

\section{Inclusion criteria}

1. Reproductive age group

2. Perimenopausal women

3. Postmenopausal women

\section{Exclusion criteria}

1. Cases of clinically palpable pelvic pathology

2. Cases of unhealthy cervix

3. Coagulation disorders

4. Pregnancy

Cases were selected according to criteria mentioned above. Also, detailed history taking and clinical examination was done. This was followed by investigations $[\mathrm{Hb}, \mathrm{BT}, \mathrm{CT}, \mathrm{TLC}, \mathrm{DLC}$, chest X-ray, ultrasound (abdomen and pelvis), urine pregnancy test, where necessary]. Informed consent of every patient was taken. Patients were advised to have a light dinner before
$10 \mathrm{pm}$ in the night prior to hysteroscopy followed by dilatation and curettage. In this study, hysteroscopy was performed under $\mathrm{I} / \mathrm{V}$ sedation and drugs used were fortwin and phenergan. The distending medium used in this study was normal saline. The device which was used in this study is: Flexible hysteroscope (Fujinon hysteroscope).

All the patients in this study underwent Diagnostic hysteroscopy followed by dilatation and curettage and the curettings were sent for histopathological examination. The results of diagnostic hysteroscopy and histopathology were studied and analyzed. Data were recorded on a predesigned proforma. Further management of the patient was decided according to age, parity, severity of disease, hysteroscopic and histopathological report.

\section{RESULTS}

This study was conducted on 100 patients. In 100 patients, who had abnormal uterine bleeding, hysteroscopy was performed along with curettage and tissue obtained was sent for histopathological examination.

Age group of the patients ranged from 22-70 years and the most common age group was $31-40$ years $(45 \%)$. This group comprised of $45 \%$ of the patients and mean age was $38.3 .88 \%$ of patients were parous and rest $12 \%$ was nulliparous. Most of the patients (34\%) presented within six months of the onset of symptoms.

Menorrhagia was the commonest presenting symptom in this study. $32 \%$ patients presented with this symptom. The next common presentation was oligomenorrhoea $(17 \%)$ and polymenorrhagia (17\%). $13 \%$ patients came with hypomenorrhoea, $7 \%$ with Post-Menopausal Bleeding (PMB) and polymenorrhoea, 5\% with metrorrhagia and $2 \%$ with menometrorrhagia. Table 1 represents the incidence of various bleeding patterens in the present study.

Table 1: Distribution of patients according to types of abnormal uterine bleeding $(n=100)$.

\begin{tabular}{|lll|} 
Type & $\begin{array}{l}\text { No. of } \\
\text { cases }\end{array}$ & $\begin{array}{l}\text { Percentage } \\
(\%)\end{array}$ \\
\hline Hypomenorrhoea & 13 & 13.0 \\
\hline Menometrorrhagia & 2 & 2.0 \\
\hline Menorrhagia & 32 & 32.0 \\
\hline Metrorrhagia & 5 & 5.0 \\
\hline Oligomenorrhoea & 17 & 17.0 \\
\hline Postmenopausal bleeding & 7 & 7.0 \\
\hline Polymenorrhagia & 17 & 17.0 \\
\hline Polymenorrhoea & 7 & 7.0 \\
\hline
\end{tabular}

Out of 100 patients, $48 \%$ were found to be normal on hysteroscopy. And rest $52 \%$ cases were abnormal. Out of 
which, 33\% of the patients had endometrial lesions and $19 \%$ had space occupying lesions. While 59\% patients were reported as normal histopathologically and rest of $28 \%$ had endometrial lesions and $13 \%$ had space occupying lesions.

On hysteroscopy, $48 \%$ of the patients had either proliferative or secretory picture which was grouped as normal. The rest $52 \%$ of patients had some abnormality. Hyperplasia was the most common finding which was seen in $26 \%$ patients. The other findings included endometrial polyp $8 \%$, myoma or myomatous polyp $7 \%$, atrophic endometrium 4\%, endometrial carcinoma, misplaced IUCD, and synechiae comprising $2 \%$ each and tubercular endometritis 1\% (Table 2).

Table 2: Distribution of the patients according to the hysteroscopic findings.

\begin{tabular}{|lll|}
\hline Finding & $\begin{array}{l}\text { No. of } \\
\text { cases }\end{array}$ & $\begin{array}{l}\text { Percentage } \\
(\%)\end{array}$ \\
\hline Normal & 48 & 48.0 \\
\hline Proliferative & 30 & 30.0 \\
\hline Secretory & 18 & 18.0 \\
\hline Hyperplasia & 26 & 26.0 \\
\hline Endometrial polyp & 8 & 8.0 \\
\hline Myoma/myomatous polyp & 7 & 7.0 \\
\hline Synechiae & 2 & 2.0 \\
\hline Misplaced IUCD & 2 & 2.0 \\
\hline Atrophic endometrium & 4 & 4.0 \\
\hline Tubercular endometritis & 1 & 1.0 \\
\hline Endometrial carcinoma & 2 & 2.0 \\
\hline
\end{tabular}

Histopathology reports of the tissue sent for biopsy came out to be normal (proliferative or secretory) in 59\% patients. Hyperplasia was reported in $20 \%$ and another $5 \%$ were reported as hormonal pattern. This was due to some treatment in the form of hormones prescribed to the patients for the abnormal uterine bleeding.
The rest consisted of endometrial polyp in 5\%, atrophic in $5 \%$, myoma in $3 \%$, endometrial carcinoma in $2 \%$ and tubercular endometritis in $1 \%$. The histopathology results are tabulated in Table 3 .

Table 3: Distribution of the patients according to the histopathological findings $(n=100)$.

\begin{tabular}{|lll|}
\hline Finding & $\begin{array}{l}\text { No. of } \\
\text { cases }\end{array}$ & $\begin{array}{l}\text { Percentage } \\
(\%)\end{array}$ \\
\hline Normal & 59 & 59.0 \\
\hline Proliferative & 35 & 35.0 \\
\hline Secretory & 24 & 24.0 \\
\hline Hyperplasia & 20 & 20.0 \\
\hline Tubercular endometritis & 1 & 1.0 \\
\hline Endometrial carcinoma & 2 & 2.0 \\
\hline Endometrial polyp & 5 & 5.0 \\
\hline Myoma/myomatous polyp & 3 & 3.0 \\
\hline Hormonal & 5 & 5.0 \\
\hline Atrophic & 5 & 5.0 \\
\hline
\end{tabular}

The hysteroscopic findings were then correlated with histopathological findings. 48 cases were found to be normal on hysteroscopy. These cases were also normal on histopathology also. Out of 26 cases of hyperplasia, only 19 were confirmed on histopathology and 3 were reported as hormonal pattern due to some treatment taken by patient and 4 were normal on histopathology. 8 cases of endometrial polyp were found on hysteroscopy. Out of these 5 were confirmed on histopathology. All the cases of atrophic endometrium were confirmed on histopathological examination. Synechiae were seen in 2 patients. Out of whom, one was reported as hormonal pattern and other as atrophic endometrium on histopathology.

Table 4 shows comparision between hysteroscopic and histopathological findings.

Table 4: Comparison between the hysteroscopic findings and the histopathological findings.

\begin{tabular}{|llllllllll|}
\hline $\begin{array}{l}\text { Hysteroscopic } \\
\text { findings }\end{array}$ & $\begin{array}{l}\text { No. of } \\
\text { cases }\end{array}$ & $\begin{array}{l}\text { Histopathological findings } \\
\text { Normal }\end{array}$ & Hyperplasia & Polyp & Myoma & Hormonal & Atrophic & TB & Ca \\
\hline Normal & 48 & 48 & 0 & 0 & 0 & 0 & 0 & 0 & 0 \\
\hline Hyperplasia & 26 & 4 & 19 & 0 & 0 & 3 & 0 & 0 & 0 \\
\hline Endometrial polyp & 8 & 3 & 0 & 5 & 0 & 0 & 0 & 0 & 0 \\
\hline Myoma & 7 & 4 & 0 & 0 & 3 & 0 & 0 & 0 & 0 \\
\hline Synechiae & 2 & 0 & 0 & 0 & 0 & 1 & 1 & 0 & 0 \\
\hline Misplaced IUCD & 2 & 1 & 0 & 0 & 0 & 1 & 0 & 0 & 0 \\
\hline Atrophic & 4 & 0 & 0 & 0 & 0 & 0 & 4 & 0 & 0 \\
\hline TB endometritis & 1 & 0 & 0 & 0 & 0 & 0 & 0 & 1 & 0 \\
\hline Endometrial Ca & 2 & 0 & 0 & 0 & 0 & 0 & 0 & 0 & 2 \\
\hline
\end{tabular}


Misplaced IUCD was found in 2 cases on hysteroscopy and endometrium of one patient was found to be normal and other had hormonal pattern histopathologically. 2 cases of endometrial carcinoma seen on hysteroscopy and were confirmed on histopathology. 1 case of tubercular endometritis was diagnosed on hysteroscopy. This was confirmed on histopathology also. 7 cases of myoma were seen on hysteroscopy. Out of these, 3 were confirmed on histopathological examination.

\section{DISCUSSION}

Menstrual dysfunction is the cause of discomfort, inconvenience and disruption of healthy lifestyle, which affects millions of women in both the developed and the developing world. Abnormal uterine bleeding is one of the most frequently encountered conditions in gynaecology. As quoted by Prentice A, ${ }^{1}$ AUB affects 10 to $30 \%$ of reproductive aged women and up to $50 \%$ of perimenopausal women.

Until recent times, the usual method of evaluating abnormal uterine bleeding was dilatation and curettage. Although the diagnosis may be obtained by this manner in most patients, yet in about $10 \%$ patients evaluated by blind curettage; may miss the focal pathology. Hysteroscopy offers a valuable extension of the gynecologist armamentarium. It can improve the diagnostic accuracy and can permit better treatment of the uterine diseases. After hysteroscopy, the elective surgery of the patient can be planned. The use of hysteroscopy in abnormal uterine bleeding is replacing the blind curettage, as it "sees" and "decides" the cause. This is because the uterine cavity can be observed and the area in question can be curetted. In fact, it is the eye in the uterus.

Table 5: Normal and abnormal finding on hysteroscopy in various studies.

\begin{tabular}{|c|c|c|c|}
\hline Author & Year & $\begin{array}{l}\text { Normal } \\
(\%)\end{array}$ & $\begin{array}{l}\text { Abnormal } \\
(\%)\end{array}$ \\
\hline Siegler $^{7}$ & 1976 & 41.7 & 58.3 \\
\hline Sciarra ${ }^{8}$ & 1977 & 28.8 & 71.2 \\
\hline Wamsteker $^{11}$ & 1984 & 42.71 & 57.29 \\
\hline $\begin{array}{l}\text { Gimpelson and } \\
\text { Rappald }^{13}\end{array}$ & 1988 & 60 & 40 \\
\hline Loffer $^{14}$ & 1989 & 48.66 & 51.44 \\
\hline Sheth $^{15}$ & 1990 & 44 & 56 \\
\hline $\begin{array}{l}\text { Parasnis and } \\
\text { Parulekar }\end{array}$ & 1992 & 76 & 24 \\
\hline Panda $^{18}$ & 1999 & 46.5 & 53.5 \\
\hline Gianninoto $^{21}$ & 2003 & 25 & 75 \\
\hline $\mathrm{deWit}^{22}$ & 2003 & 54.2 & 45.8 \\
\hline Jyotsana $^{23}$ & 2004 & 34 & 66 \\
\hline Barati ${ }^{24}$ & 2008 & 78.2 & 21.8 \\
\hline Patil $^{25}$ & 2009 & 50 & 50 \\
\hline $\mathrm{Gita}^{26}$ & 2011 & 26 & 74 \\
\hline Present study & 2013 & 48 & 52 \\
\hline
\end{tabular}

This study was undertaken to correlate the hysteroscopic findings with histopathological report and also to study the accuracy of hysteroscopy in evaluation of abonormal uterine bleeding. The results of various authors are shown in tables.

In the present study, hysteroscopy showed normal findings in $48 \%$ cases and abnormal in $52 \%$. The Table 5 compares abnormal and normal findings in hysteroscopy in various studies.

In the present study, $48 \%$ cases were diagnosed as normal on hysteroscopy and all of these cases were confirmed on histopathological examination. Hence, the value of hysteroscopy in diagnosing a normal endometrium is high.

\section{Proliferative endometrium}

In 30 patients, endometrium was pink, smooth and thin, appearing to be of proliferative type. The same was confirmed by histopathology in 28 patients. Histology of the endometrial curetting revealed proliferative endometrium with tall columnar cells and pseudo stratification. Findings were different in 2 cases. Therefore, the diagnostic accuracy of hysteroscopy for proliferative endometrium was $93.3 \%$.

Sensitivity, specificity, positive predictive value and negative predictive value of hysteroscopy for proliferative endometrium compared to histopathology were $80 \%, 96.9 \%, 93.3 \%$ and $90 \%$ respectively.

\section{Secretory endometrium}

Hysteroscopy proved uterine cavity to be normal with orange, undulating and thick endometrium appearing to be secretory in 18 cases. The diagnostic accuracy of hysteroscopy for secretory endometrium was $94.4 \%$.

So, sensitivity, specificity, positive predictive value and negative predictive value of hysteroscopy for secretory endometrium were $70.8 \%, 98.7 \%, 94.4 \%$ and $91.5 \%$ respectively.

\section{Endometrial hyperplasia}

In these patients, endometrium appeared to be thickened, edematous and undulating. There were 26 patients with these hysteroscopic findings. This finding was consistent with histology of the endometrium in 19 cases and different in 7 cases.

In the present study, $26 \%$ patients were labeled hysteroscopically as endometrial hyperplasia. Out of these, 19 were proved to be endometrial hyperplasia without atypia on histopathological examination; 3 cases had a histopathological picture which could not be commented upon and this was because of the hormonal treatment taken by the patients and rest of the 4 cases was reported as normal endometrium. It was difficult by 
hysteroscopy to differentiate between late secretory endometrium and endometrial hyperplasia.

However, on histopathological examination, only 19 cases out of 26 could be confirmed as endometrial hyperplasia giving a percentage of accuracy of hysteroscopy as $73.1 \%$ in the present study. This is in agreement with the findings of Patil et al. ${ }^{25}$ who reported an accuracy of $72 \%$.

Also, sensitivity, specificity, positive predictive value and negative predictive value were $95 \%, 91.3 \%, 73.1 \%$ and $98.7 \%$ respectively. Loverro et al. $^{27}$ stated sensitivity, specificity, positive predictive value and negative predictive value as $98 \%, 95 \%, 63 \%$ and $99 \%$ respectively which is comparable with the present study. Table 6 shows incidence of hyperplasia in various studies.

Table 6: Incidence of endometrial hyperplasia in various studies.

\begin{tabular}{|lll|} 
Author & Year & $\begin{array}{l}\text { Endometrial } \\
\text { hyperplasia } \\
(\%)\end{array}$ \\
\hline Barbot $^{9}$ & 1980 & 19.7 \\
\hline Wamsteker $^{11}$ & 1984 & 12.5 \\
\hline Saraiya $^{17}$ & 1994 & 15.2 \\
\hline Panda $^{18}$ & 1999 & 28.3 \\
\hline Jyotsana $^{23}$ & 2004 & 22.66 \\
\hline Patil $^{25}$ & 2009 & 20 \\
\hline Gita $^{26}$ & 2011 & 30 \\
\hline Present study $^{25}$ & 2013 & 26 \\
\hline
\end{tabular}

\section{Endometrial polyp}

In $8(8 \%)$ patients on hysteroscopy, small growths in the uterine cavity, which were soft, oval, pedunculated with a smooth surface were seen. These growths appeared as endometrial polyps. The histopathology report confirmed the findings in 5 cases. These remaining 3 cases were confirmed later after hysterectomy as endometrial polyp.

Table 7: Incidence of endometrial polyp various studies.

\begin{tabular}{|c|c|}
\hline Author & $\begin{array}{l}\text { Endometrial } \\
\text { polyp }(\%)\end{array}$ \\
\hline Mencaglia $^{12}(1987)$ & 9.8 \\
\hline Saraiya $^{17}(1994)$ & 10.5 \\
\hline Panda $^{18}(1999)$ & 10 \\
\hline Van Trotsenburg $^{19}(2000)$ & 14 \\
\hline $\operatorname{deWit}^{22}(2003)$ & 14.4 \\
\hline Jyotsana $^{23}(2004)$ & 20 \\
\hline Patil $^{25}(2009)$ & 9 \\
\hline Present study & 8 \\
\hline
\end{tabular}

The diagnostic accuracy of hysteroscopy for endometrial polyp when compared to histopathology was $62.5 \%$. So, sensitivity, specificity, positive predictive value and negative predictive value of hysteroscopy for endometrial polyp compared to histopathology were $100 \%, 96.8 \%$, $62.5 \%$ and $100 \%$ respectively. But compared to the final diagnosis, sensitivity, specificity, positive predictive value and negative predictive value were $100 \%$ each. Panda et al. ${ }^{18}$ reported accuracy of $100 \%$ in diagnosing polyp. Patil et al. ${ }^{25}$ also reported the accuracy of hysteroscopy for endometrial polyp as $100 \%$ which is same as in the present study. Table 7 shows incidence of endometrial polyp in various studies.

\section{Myoma/myomatous polyp}

A white-colored bulge, round in shape, with a smooth surface, which was diagnosed on hysteroscopy as myoma, was found in 7 patients. The reported incidence varies from $5.9 \%$ to $21 \%$ in various studies. Table 8 shows incidence of myoma in various studies.

Table 8: Incidence of myoma in various studies.

\begin{tabular}{|lll|}
\hline Author & Year & $\begin{array}{l}\text { Incidence } \\
\text { of myoma }\end{array}$ \\
\hline Mencaglia $^{12}$ & 1987 & $9.6 \%$ \\
\hline Panda $^{18}$ & 1999 & $6.6 \%$ \\
\hline Van Trotsenburg & 2000 & $14 \%$ \\
\hline Madan $^{20}$ & 2001 & $5.9 \%$ \\
\hline deWit $^{22}$ & 2003 & $21 \%$ \\
\hline Jyotsana $^{23}$ & 2004 & $17.33 \%$ \\
\hline Patil $^{25}$ & 2009 & $6.6 \%$ \\
\hline Gita $^{26}$ & 2011 & $16 \%$ \\
\hline Present study & 2013 & $7 \%$ \\
\hline
\end{tabular}

Out of these 7 cases, only 3 were confirmed on histopathological examination. Thus, the diagnostic accuracy of hysteroscopy for myoma was $42.9 \%$. The remaining 4 cases were confirmed on hysterectomy specimen. Therefore, considering the final diagnosis, diagnostic accuracy of hysteroscopy was $100 \%$. So, sensitivity, specificity, positive predictive value and negative predictive value of hysteroscopy for myoma compared to histopathology were $100 \%, 95.9 \%, 42.9 \%$ and $100 \%$ respectively. Therefore, compared with final diagnosis, sensitivity, specificity, positive predictive value and negative predictive value of hysteroscopy for myoma were $100 \%$ each. Similar findings were reported by Panda et al. ${ }^{18}$ and Patil et al. ${ }^{25}$

\section{Atrophic endometrium}

In $4(4 \%)$ patients, the endometrium appeared flat, thin and fragile. At some points, petechie and haemorrhages were present. The tubal ostia were very prominent. The picture was suggestive of atrophic endometrium, which was also confirmed by histopathology in all cases. The present study found atrophic endometrium in $4 \%$ cases. The reported incidence varies from $1.4 \%$ to $12 \%$ in various studies. Table 9 shows the incidence of atrophic endometrium in various studies. 
Table 9: Incidence of atrophic endometrium in different studies.

\begin{tabular}{|lll|} 
Author & $\begin{array}{l}\text { Incidence of } \\
\text { Year }\end{array}$ & $\begin{array}{l}\text { atrophic } \\
\text { endometrium }\end{array}$ \\
\hline Barbot $^{9}$ & 1980 & $1.4 \%$ \\
\hline Mencaglia $^{12}$ & 1987 & $12 \%$ \\
\hline Panda $^{18}$ & 1999 & $5 \%$ \\
\hline Patil $^{25}$ & 2009 & $8 \%$ \\
\hline Present study & 2013 & $4 \%$ \\
\hline
\end{tabular}

Therefore, the diagnostic accuracy of hysteroscopy for atrophic endometrium was $100 \%$. Thus, the sensitivity, specificity, positive predictive value and negative predictive value were $100 \%$ each. Panda et al. ${ }^{18}$ also reported accuracy of $100 \%$ which is comparable with present study.

\section{Synechiae}

There were $2 \%$ cases in the present study which had synechiae seen on hysteroscopy. Both of these cases had flimsy adhesions which were divided by hysteroscope itself. Wamsteker ${ }^{11}$ and Panda et al. ${ }^{18}$ reported the incidence of synechiae in $3 \%$ and $1 \%$ cases respectively which is comparable with the present study.

The histopathological examination of the tissue sent for biopsy showed atrophic endometrium in one and hormonal pattern in the other. This was probably due to the difference in the tissue obtained during biopsy from the endometrium after the division of the adhesions. Therefore, the diagnostic accuracy of hysteroscopy for synechiae was $100 \%$. So, sensitivity, specificity, positive predictive value and negative predictive value were $100 \%$ each.

\section{Tuberculous endometritis}

In the present study, tuberculous endometritis was detected in $1 \%$ cases as evidenced by the presence of tubercles and caseous material in the uterine cavity. The histopathological examination of the tissue sent for biopsy confirmed the diagnosis.

Thus, the diagnostic accuracy of hysteroscopy for the tuberculous endometritis was $100 \%$. Therefore, the sensitivity, specificity, positive predictive value and negative predictive value of hysteroscopy for the tuberculous endometritis compared to histopathology were $100 \%$ each.

\section{Carcinoma endometrium}

In $2(2 \%)$ patients, hyperplasia with polypoidal growth, areas of ulceration, haemorrhage and increased vascularity were labelled as carcinoma endometrium on hysteroscopy. Both cases were confirmed on histopathological examination.
The incidence of carcinoma endometrium in the present study is comparable with other studies as shown in Table 10 .

Table 10: Incidence of carcinoma endometrium in various studies.

\begin{tabular}{|ll|}
\hline Authors & $\begin{array}{l}\text { Incidence of } \\
\text { carcinoma } \\
\text { endometrium }\end{array}$ \\
\hline Valle $^{10}(1981)$ & $0.53 \%$ \\
\hline Jyotsana $^{23}(2004)$ & $1.3 \%$ \\
\hline Patil $^{25}(2009)$ & $2 \%$ \\
\hline Present study & $2 \%$ \\
\hline
\end{tabular}

The diagnostic accuracy of hysteroscopy for carcinoma endometrium was $100 \%$. So, the sensitivity, specificity, positive predictive value and negative predictive value were $100 \%$ each. Mencaglia et al. ${ }^{12}$ combined hysteroscopy with endometrial biopsy for diagnosing endometrial carcinoma and found nearly $100 \%$ accuracy in the diagnosis of endometrial neoplasia and its precursors. Panda et al. ${ }^{18}$ found $100 \%$ accuracy of hysteroscopy for endometrial carcinoma in his study. Patil et al. ${ }^{25}$ found $67 \%$ accuracy of hysteroscopy for carcinoma endometrium. Thus, the accuracy of hysteroscopy for endometrial carcinoma in the present study is comparable with other studies.

\section{Misplaced IUCD}

$2 \%$ cases in the present study were found to have an IUCD in their uterine cavity. In both of these cases the threads were broken and the patient had thought that she had expelled the device. The histopathological examination of the tissue sent for biopsy showed normal endometrium in one and hormonal pattern in the other. This is because one patient was using progesterone containing IUCD. Thus, the diagnostic accuracy of hysteroscopy for IUCD was $100 \%$. Therefore, sensitivity, specificity, positive predictive value and negative predictive value were $100 \%$ each. Patil et al. ${ }^{25}$ found $100 \%$ accuracy in detecting IUCD. Thus, the results are comparable.

\section{Accuracy of hysteroscopy}

Out of the endometrial lesions, the accuracy of hysteroscopy was $100 \%$ in diagnosing normal endometrium (not withstanding the histological confirmation as proliferative or secretory), atrophic endometrium, tuberculous endometritis and endometrial carcinoma. However, the accuracy of hysteroscopy for diagnosing the hyperplastic endometrium was $73.1 \%$.

Hysteroscopy was more accurate in identifying the intrauterine pathologies like endometrial polyp, myoma and misplaced IUCD than histopathology. Histopathology had $100 \%$ accuracy in diagnosing endometrial hyperplasia, endometrial carcinoma and tubercular endometritis. 
Thus, the overall sensitivity, specificity, positive predictive value and negative predictive value of hysteroscopy as compared to histopathology is $97.56 \%$, $79.66 \%, 76.92 \%$ and $97.92 \%$ respectively.

\section{CONCLUSION}

Hysteroscopy is a valuable, simple, low risk technique which allows an adequate exploration of the uterine cavity under visual control. It ensures speed and safety with the diagnosis and treatment. The results are immediately available. In patients with abnormal uterine bleeding, hysteroscopy provides the possibility of immediate diagnosis and prompt and effective treatment. It allows finding out the source of bleeding and perform a directed biopsy of the suspected area. It affords a more accurate diagnosis than dilatation \& curettage for intrauterine pathologies. But for hyperplasia, carcinoma endometrium and tubercular endometritis, histopathology gives confirmative tissue diagnosis in all cases. Therefore, it can be concluded that hysteroscopy offers an invaluable advantage of direct visualization of any abnormality within the uterine cavity. It does not substitute other diagnostic procedures; rather, it complements them. Hysteroscopy is a safe, simple, quick and economic technique, well accepted by the patient, with great potential in gynaecology. Hysteroscopy has a high sensitivity i.e. it can supplement and enhance the accuracy of tissue diagnosis. So, hysteroscopically directed biopsy would be an ideal procedure in abnormal uterine bleeding wherever facilities are available.

Funding: No funding sources

Conflict of interest: None declared

Ethical approval: Not required

\section{REFERENCES}

1. Prentice A. When does heavy flow merit treatment? Practitioner. 2000;244:179-82.

2. Nicholson WK, Elison SA, Grason H, Powe NR. Patterns of ambulatory care use for gynaecologic conditions: a national study. Am J Obstet Gynaecol 2001;184(4):523-30.

3. Goodman A. Abnormal genital tract bleeding. Clin Cornerstone. 2000;3(1):25-35.

4. Baggish MS, Valle RF, Guedj H. Office hysteroscopy. In: Baggish MS, Valle RF, Guedj H, eds. Visual Perspectives of Uterine Anatomy, Physiology and Pathology. 3rd ed. Philadelphia: Lippincott Williams and Wilkins; 2007: 213- 225.

5. Word B, Gravlee LC, Wideman GL. The fallacy of simple uterine curettage. Obstet Gynaecol. 1958;12(6):642-8.

6. Baggish MS. Operative hysteroscopy. In: Rock JA, Jones HW III, eds. Telinde's Operative Gynaecology. 9th ed. Philadelphia: Lipincott Williams \& Wilkins; 2003: 339-411.
7. Siegler AM, Kemmann EK, Gentile GP. Hysteroscopic procedures in 257 patients. Fertil Steril. 1976;27(11):1267-73.

8. Sciarra JJ, Valle RF. Hysteroscopy: a clinical experience with 320 patients. Am J Obstet Gynaecol. 1977;127(4):340-8.

9. Barbot J, Parent B. Contact hysteroscopy: another method of endoscopic examination of the uterine cavity. Am J Obstet Gynaecol. 1980;136(6):721-6.

10. Velle RF. Hysteroscopic evaluation of patients with abnormal uterine bleeding. Surg Gynaecol Obstet. 1981;153(4):521-6.

11. Wamsteker K. Hysteroscopy in the management of abnormal uterine bleeding in 199 patients. In: Seigler AM, Lindemann HJ, eds. Hysteroscopy: Principles and Practice. 1st ed. Philadelphia: JB Lippincott; 1984: 128-131.

12. Mencaglia L, Pernio A, Hamou J. Hysteroscopy in peri-menopausal and postmenopausal women with abnormal uterine bleeding. J Reprod Med. 1987;32(8):577-82.

13. Gimpelson RJ, Rappold HO. A comparative study between panoramic hysteroscopy with directed biopsies and dilatation and curettage. A review of 276 cases. Am J Obstet Gynaecol. 1988;158(3):48992.

14. Loffer FD. Hysteroscopy with selective endometrial sampling compared with $\mathrm{D}$ and $\mathrm{C}$ for abnormal uterine bleeding: the value of a negative hysteroscopic view. Obstet Gynaecol. 1989;73(1):1620.

15. Sheth SS, Nerurkar NM, Mangeshkar PS. Hysteroscopy in abnormal uterine bleeding. J Obstet Gynaecol India. 1990;40:451.

16. Parasnis HB, Parulekar SV. Significance of negative hysteroscopic view in abnormal uterine bleeding. $\mathbf{J}$ Postgrad Med. 1992;38(2):62-4.

17. Saraiya S, Sherian N, Walvekar UR. Hysteroscopy in abnormal uterine bleeding. J Obstet Gynaecol India. 1994;44(6):950-9.

18. Panda A, Parulekar SV, Gupta A. Diagnostic hysteroscopy in abnormal uterine bleeding and its histopathological correlation. J Obstet Gynaecol India. 1999;175:74-6.

19. van Trotsenburg M, Wieser F, Naegle F. Diagnostic hysteroscopy for the investigation of abnormal uterine bleeding in premenopausal patients. Contrib Gynaecol Obstet. 2000;20:21-6.

20. Madan SM, Al-Zufairi ZA. Abnormal uterine bleeding: diagnostic value of hysteroscopy. Saudi Med J. 2001;22(2):153-6.

21. Gianninoto A, Morana C, Campione C. Diagnostic hysteroscopy in abnormal uterine bleeding. Five year's experience. Minerva Gynaecol. 2003;55(1):5761.

22. deWit AC, Vleugels MP, deKruif JH. Diagnostic hysteroscopy: A valuable diagnostic tool in the diagnosis of structural intra-cavital pathology and endometrial hyperplasia or carcinoma? Six year's of experience with nonclinical diagnostic hysteroscopy. 
Eur J Obstet Gynaecol Reprod Biol. 2003;110(1):7982.

23. Jyotsana, Manhas K, Sharma S. Role of hysteroscopy and laparoscopy in evaluation of abnormal uterine bleeding. J K Sci. 2004;6:23-7.

24. Barati M, Masihi S, Maroamezi F. Office hysteroscopy in patients with abnormal uterine bleeding and normal transvaginal sonography. Royal Inst Int J Fertil Steril. 2008;1:175-8.

25. Patil SG, Bhute SB, Inamdar SA, Acharya NS, Shrivastava DS. Role of diagnostic hysteroscopy in abnormal uterine bleeding and its histopathologic correlation. J Gynaecol Endosc Surg. 2009;1:98-104.
26. Gita G, Surpreet S, Arvind L, Shashi K. Hysteroscopy in evaluation of abnormal uterine bleeding. J Obstet Gynaecol India. 2011;61(5):546-9. 27. Loverro G, Bettocchi S, Cormio G, Nicolardi V, Porreca MR, Pansini N et al. Diagnostic accuracy of hysteroscopy in endometrial hyperplasia. Maturitas. 1996;25(3):187-91.

DOI: $10.5455 / 2320-1770 . i j \mathrm{rcog} 20140918$

Cite this article as: Singh S, Taneja BK, Singh P, Ahlawat R. Role of diagnostic hysteroscopy in abnormal uterine bleeding. Int J Reprod Contracept Obstet Gynecol 2014;3:544-51. 